\section{SEX EDUCATION AND GUIDANCE}

$\mathbf{M}$ ANY centuries have passed since Alcuin of York wrote that "Since the time of King Aelfwold ... the land has been absolutely submerged under a flood of fornication, adultery and incest, so that the very semblance of modesty is entirely absent", but variations on the same theme are still played to-day. Since the outbreak of the War, indeed, they have been both numerous and persistent. In part, such dismal wailings may be discounted as the product of present-day tension and upheaval, but after all allowance has been made for this, a nucleus of truth remains. It is a fact that conditions of war almost invariably lead to an increase in sexual promiscuity, and even the least bigoted among us can scarcely fail to be disquieted.

But while it is such war-time behaviour, with its resulting increased incidence of venereal infection, which has at long last been responsible for removing the taboo on public discussion of sex and sexual behaviour, the problem is not in essence a purely war-time one. In the long run, our hopes for the development of a healthy attitude to sex in our society must be based not only on economic and social change, but also on rational and fearless education. The importance of the latter is clearly recognized by the Board of Education, and its recent pamphlet on the subject* will be given a warm welcome by all progressive educationists.

For many years individual education authorities, schools and youth elubs have been undertaking sex education, and some have done excellent work in this field. This is, however, the first occasion upon which the Board has given so clear a lead ; and many who were wondering whether or not to go ahead will no doubt do so under this new impetus. It is important that those who do should be very careful, in carrying out this most valuable but rather difficult work, that they adopt methods likely to produce the best results. Not all the efforts in this field in the past have been entirely happy in their conception or fortunate in their results, and thereby the cause of sex education has sadly suffered. It is, therefore, particularly gratifying to note that the Board of Education itself proposes "both to conduct a special course in the near future, which it is hoped may help a number of men and women to assist in local courses, and to deal with this matter where appropriate in other courses that they organise". No doubt advantage will be taken of the experience of those who have for some years specialized in this field, and local education authorities are in fact advised to apply for help to the Central Council for Health Education, which has for some time been providing lecturers, literature, films and general advice.

The pamphlet is in the main based upon the results of inquiries recently made by 'H.M. Inspectorate, and.

* Board of Education. Educational Pamphlet No. 119. "Sex Education in Schools and Youth Organizations." (London: H.M. Stationery Office, 1943.) 6d. net. presents an interesting survey of present practice in this sphere. Apparently, about "a third of the secondary schools in the country make a serious attempt to give instruction", while "the remaining two-thirds of the schools are about equally divided between those who give slight attention to the subject or avoid it altogether". So far as the elementary schools are concerned, "it would appear that in the areas of approximately half the Local Education Authorities in England, and to a lesser extent in Wales, there is carefully planned instruction in at least a few of the schools"; while in other areas, "perhaps one-third of the country ... practically nothing is done". It is interesting also to observe that "approximately three girls' schools include sex instruction in their syllabus for every one boys' school"-a conclusion that confirms the strong im. pression to that effect previously held by those who have been concerned in this work.

Excellent in quality as much of this work is, educationists cannot rest content until the great gaps are filled in, and the standard of all such teaching raised to that of the best. The facts gathered by the inspectorate make it very clear that the methods adopted vary widely, and perhaps this is well, for we have as yet insufficient experience to lay down the law about their relative merits. What does seem to be clear, however, is that the instruction should be fitted as inconspicuously as possible into the ordinary school routine, and that sex education is conspicuous in a school only in proportion to tsimperfection. In many places, where the staff feils unable or unwilling to incorporate sex education en their day-by-day lessons, recourse is had to the seir vices of the specialist lecturers of the Central Council for Health Education; but this Council itself recog. nizes that such a method is very far from ideal and can be regarded only as a temporary expedient. This makes it particularly important for local educa. tion authorities to arrange courses for their teachers, both to provide the non-biologists among them with the necessary factual knowledge, and to make sug. gestions about methods of classroom presentation. Apart from courses on biology and health education generally, special courses on sex education have either already been held, or are at present being arranged, for the teachers of Surrey, Middlesex, West Sussex and Dorset among the counties; Dews. bury, Doncaster and Bristol among the county boroughs; and an occasional progressive urban district like Enfield. It is also clear, from the con. ferences which have been held elsewhere, that many more teachers' courses will materialize before long.

So far as the schools are concerned, the most important task is the presentation of simple but accurate biological information. "But early instruc. tion in the physiology of sex is only the beginning of sex education in the fullest sense. It should be succeeded at the later end of adolescence by in. struction and advice directed to the understanding and control of sexual impulse and emotion, leading on to the establishment of mutual understanding and respect between the sexes, and, as young manhood 
or womanhood is approached, to an adequate preparation for marriage". The early school-leaving age in Great Britain means that for the great majority of children the schools can do little in this respect, but the youth organizations have a great opportunity. Here the objections to visiting lecturers, which are so potent in the case of schools, scarcely apply, and the usual procedure is for a course of three or four talks illustrated by films to be given by a member of the staff of the Central Council for Health Education. Some idea of the extent of this particular part of the work now going on throughout Great Britain is given by the fact that during the six months of April-September 1943, there have been held 578 such meetings, attended by 16,223 young people.

The Board of Education pamphlet emphasizes that youth leaders "themselves require more accurate and comprehensive knowledge than they already possess". "To meet this need both local education authorities and the youth organisations are increasingly arranging short training courses in sex education for leaders, or are devoting attention to the subject at their general youth service courses." A particularly interesting course was that held recently at Horsham. A carefully selected group of leaders attended a residential week-end school, and at sessions attended by the County Director of Education, Medical Officer and Youth Organizer, a team of speakers dealt with many aspects of sex education in youth organizations. It is likely that as a result of the school, a county panel of recognized lecturers will be drawn up ; they should be able to carry out much valuable instruction in the youth organizations of West Sussex.

Particularly in respect of sex education in schools, the fear has sometimes been expressed that there may be parental opposition. Figures collected recently show this fear to be quite unfounded. Some schools and education authorities have, before introducing such lessons, circularized parents of pupils and given them the opportunity of withdrawal. Whether in fact this is a wise procedure is a matter of debate, but the numerical results are quite conclusive. Of 620 pupils from a girls' grammar school in Dorset, only two were withdrawn; of 500 in a similar school in Surrey, four; of 550 in a similar school in Kent, none. A boys' grammar school in Lancashire has given such instruction for some years, with never a single withdrawal; of 470 pupils in a similar school in 'Surrey, the parents of 380 actually wrote to give approval and to enclose a contribution towards the expenses of the lecturer. The story in senior schools is similar. A Lancashire urban district had twentyone withdrawals out of 936, and a neighbouring county borough but fifteen out of 2,300 . There is indeed a wealth of support for the pamphlet's assertion that "parents welcome any initiative shown by teachers".

Particularly welcome is the Board's recognition, that "the first responsibility rests upon parents to deal with their children's questions from the beginning, as and when they arise, in a natural manner". This, however, raises a serious problem - that of fitting the majority of parents to do so.
It is not usually recognized by scientific men that for nine parents out of ten this is at present rendered extremely difficult, even neglecting consideration of emotional unsuitability, by the simple matter of ignorance of the necessary minimum of technical vocabulary.

It is an unfortunate fact that during the last few hundred years the old Anglo-Saxon terms for the sexual organs and the sexual processes have descended far in the social scale, and in many cases have now reached the gutter. Precisely those parents who would be most willing to answer their children's queries will be most reluctant to do so in the only sexual language they know. A warm welcome must therefore be accorded to the pamphlet's suggestion for 'The organisation of parents' meetings, with a view to securing their co-operation in anything that is done through the schools, and to helping them in dealing themselves with their own children in this matter". Actual lectures on the physiology and psychology of sex, and on sex guidance to classes of parents, would also seem worth trying. The children's problems are cropping up at all times, and it therefore seems undesirable that in the long run everything should be left to the teacher.

Perhaps the main criticism that can be levelled against this publication is its almost complete scholastic isolation and neglect of the social forces involved as determinants of sexual attitudes and behaviour. The prefatory note refers to "the immediate problem, presented by the increased number of young persons who fall victims to the special temptations and circumstances of war-time", and expresses the excellent hope that further efforts will be made "to bring such persons within the influence of the Youth Service". But there is no mystical quality to the phrase 'youth service' which will enable it to conquer its environment. All sorts of social changes will be needed before sex education can yield its fullest fruits. The economic barriers to early marriage must go, and we must so conduct our society that millions of homes are not periodically broken up. Young people must be given some burning sanse of social purpose, some feeling that they can be of real service to the community and be valued by it, some belief in a future for which it is worth while to sacrifice immediate sensual gratification. Sex education cannot thrive in vacuo. It must be sex education for a particular social setting.

Some educationists may feel a certain disappoint. ment at the benign impartiality of the Board in this pamphlet, and may regret that more detailed and positive suggestions are not given as to teaching technique. But this would be a matter not so much for a pamphlet as for a book, and even a book could do little more than skim over the surface of the many problems involved. There is, moreover, a real danger in the presentation by a Government department of too detailed suggestions, the danger of stifling local initiative and experiment; and if this pamphlet does nothing more than to stimulate such experiment and initiative; the Board of Education will have rendered a great service. 